\title{
Neglected premotor neglect
}

\author{
Styrmir Saevarsson ${ }^{1 *}$, Simone Eger ${ }^{1,2}$ and Maria Gutierrez-Herrera ${ }^{1,3}$ \\ ${ }^{1}$ Clinical Neuropsychology Research Group (EKN), Department of Neuropsychology, Bogenhausen Academical Hospital, Munich, Germany \\ ${ }^{2}$ Department of Psychology, University of Innsbruck, Innsbruck, Austria \\ ${ }^{3}$ Department Biology II Neurobiology, Graduate School of Systemic Neurosciences, University of Munich (LMU), Munich, Germany \\ *Correspondence: styrmir.saevarsson@gmail.com
}

Edited by:

Srikantan S. Nagarajan, University of California, San Francisco, USA

Reviewed by:

Kelly Westlake, University of Maryland School of Medicine, USA

Keywords: premotor neglect, directional action neglect, lesion-symptom mapping, neuroanatomy, assessment methods, neglect therapy

Unilateral neglect, or neglect for short, is commonly described as the failure to respond and attend to stimuli presented on the contralesional side. It cannot be explained by primary motor and sensory impairment (Heilman et al., 1987), and is usually caused by a stroke. Although neglect patients often recover spontaneously within several weeks, they demonstrate poorer amelioration and require longer hospitalizations following a stroke compared to stroke patients without the affliction (e.g., Buxbaum et al., 2004; Gillen et al., 2005). Many different subforms of neglect have been specified to date (e.g., Saevarsson et al., 2011). One of these, premotor neglect (PMN; also known as intentional motor neglect, directional action neglect, etc.; see Saevarsson, 2013a) denotes an intentional, voluntary, and directional (e.g. eye, hand, and head) motor bias from the ipsilesional side to an object in the contralesional side of space (Watson et al., 1978; Halligan and Marshall, 1989; Bisiach et al., 1990; Goodale et al., 1990; Heilman et al., 2008; Saevarsson, 2013a). For instance, patients may fail to reach an apple on their left side with their right hand (i.e., directional akinesia; Heilman et al., 1987) although they may be visually aware of the object. The foundation of PMN diagnosis is based on various studies that indicate performance improvement or decline when patients perform tasks that require directional movements under different visual conditions (see Saevarsson, 2013a for discussion). PMN is often seen alongside other neglect forms (in approximately $45 \%$ of cases), although exact incidence has not been specified (Saevarsson, 2013a). Unfortunately, many neglect reviews and empirical studies ignore PMN altogether (e.g., Saevarsson et al., 2008; Karnath, 2014), or report it merely as an unimportant accompaniment and not specific to neglect (e.g., Himmelbach and Karnath, 2003; Rossit et al., 2009a; Striemer and Danckert, 2013). For example, Himmelbach et al. (2007, p. 1980) claim that PMN is not a "consequence of spatial neglect but rather indicate[s] a phenomenon occurring in some of these patients as well as in other stroke patients (without neglect), i.e., a phenomenon occurring with (so far not further identified) brain damage." In line with this view, the number of studies on PMN have decreased considerably since the 1990s (Saevarsson, 2013a). Conversely, many authors argue for the importance of PMN (e.g., Mattingley and Driver, 1997; Konczak and Karnath, 1998; Vossel et al., 2010; Saevarsson, 2013b) although nonneglect-based terms such as directional hypokinesia are often used. For instance, the most commonly applied neglect definition of Heilman et al. (1987) refers to PMN when describing the affliction. Controversially, current mainstream literature does not reject this description despite the fact that some authors seem to prefer "spatial" or "hemispatial" neglect as a synonym, although representational neglect is non-spatial in nature. The nature of PMN is poorly understood and may hold the key to advanced neglect assessment and rehabilitation (Punt and Riddoch, 2006; Saevarsson, 2013a), thus we argue for the existence and importance of PMN with regard to various clinical, neuroanatomical, and methodological issues.
Previous studies questioning the importance of PMN suffer from significant methodological limitations. This is partially due to difficulties in differentiating between similar PMN and visual neglect symptoms (see Saevarsson, 2013a for discussion). Performance on standard and PMN tests can be interpreted as indicating visual neglect (i.e., failure to notice items on the left side; e.g., Làdavas et al., 1993) and PMN (see Mattingley and Driver, 1997; Saevarsson, 2013a). Rossit et al. (2009a,b) revealed that stroke patients with and without neglect showed similar impaired reaches to the left side. They concluded that the directional reaching deficits were nonneglect-specific (see also Himmelbach and Karnath, 2003; see Kim et al., 2013 for similar findings and methods but different interpretation of PMN). Noticeably, they report only the group results with high standard errors on their reaching tasks. It is therefore uncertain how the patients performed individually. In other words, it is not clear what percentage of the groups demonstrated reaching deficits to the contralesional side. It is important in this context that not all patients indicate PMN symptoms; therefore, it is uncertain whether a group of patients is representative of PMN. In other words, by diluting the group with patients who do not suffer from PMN, it is not likely to reveal any difference in PMN testing between two groups of right-brain damaged patients that do and do not have neglect (Rorden et al., 2007). This would be evident in a group of neglect patients in which none or only few suffered from PMN. Similarly, Himmelbach and Karnath (2003) criticize various studies (e.g., Husain et al., 2000) 
that compare reaching deficits in rightbrain damaged neglect patients to healthy subjects. To test this point empirically, it would be questionable, for instance, to evaluate a group of patients with neglect in order to explore motor neglect since only a proportion of patients with neglect suffer from motor neglect (Saevarsson, 2013a). Or in Brewer's (1994, p. 119) words: "It is a mistake, in my view, to try to unify the wide variety of phenomena classified as manifestations of "neglect," by appeal to a single diagnostic or explanatory model of the neglect deficit." Moreover, Rossit et al. (2009b,a) used mainly the Behavioral Inattention Test (BIT; Wilson et al., 1987) to diagnose neglect in right-hemisphereinjured patients. It is debatable whether to divide participants into neglect and non-neglect subgroups when using the BIT as it does not provide an adequate assessment unless used alongside additional diagnostic resources that are not sensitive to personal and extrapersonal neglect; in addition, the BIT cannot distinguish between the motor and perceptive components of neglect (Plummer et al., 2003). No cut-off scores are given for the BIT and no clear evidence exists for its validity (Cermak and Hausser, 1989). Additionally, therapists sometimes complain that patients perform well on the BIT although their neglect manifests itself clearly in more stressful circumstances in daily life (e.g., Hjaltason and Saevarsson, 2007).

Neuroanatomical evidence against the existence of PMN is infirm and contradictory. Rossit et al. (2009a,b) highlight nodes in the basal ganglia, occipito-parietal cortex, and frontal lobe as being responsible for directional reaching deficits in stroke patients, and claim that these areas are not associated with neglect per se, citing the neuroanatomical findings of Karnath et al. $(2001,2004)$ and Mort et al. (2003). Furthermore, Rossit et al. indicate that damage in the inferior parietal cortex involved in reaching and awareness deficits to the left side was also responsible for directional reaching deficits without neglect. Similarly, Himmelbach and Karnath (2003) hypothesize that the posterior parietal and superior temporal cortex are responsible for directional reaching, and the inferior parietal lobe and superior temporal cortex produce spatial neglect and directional reaching deficits. Many areas of the brain, such as the inferior parietal cortex, temporo-parietal junction (e.g., Mort et al., 2003), superior temporal cortex (Karnath et al., 2004), frontal lobe (Husain and Kennard, 1996; Ghacibeh et al., 2007), and basal ganglia (Karnath et al., 2002; Vossel et al., 2010) are widely believed to be involved in neglect. Therefore, Rossit and Himmelbach et al.'s perspectives differ significantly from other neuroanatomical studies. In other words, by indicating a common neuroanatomical mechanism (e.g. Mattingley et al., 1998; Muggleton et al., 2006), Rossit and others may explain isolated reaching deficits to the left side in neglect. Moreover, Karnath et al. $(2001,2004)$ and Mort et al. (2003) did not control for directional motor deficits in their studies, therefore making a comparison to the studies of Rossit and Himmelbach and others impossible. Phrased differently, lesion-symptom mapping of two different groups requires symptoms that differ in order to be able to map the area of interest (Rorden et al., 2007). Furthermore, Rossit et al.'s (2009a,b) and Himmelbach and Karnath's (2003) sample sizes were only 11,11 , and six neglect patients, respectively, which is likely too small for a meaningful lesion-symptom study. Statistical power is a major concern due to the location distribution of brain lesions (Kimberg et al., 2007). Crucially, there is currently no final agreement on the critical neuroanatomical bases of neglect and PMN due to various methodological assessment issues (see Danckert and Ferber, 2006; Saevarsson, 2013a,b; Saevarsson and Kristjánsson, 2013).

To account for this discrepancy, it is suggested that directional motor deficits observed in right-brain injured patients "without neglect" (who may not suffer from peripersonal visual neglect) indicate PMN that is not coupled with peripersonal visual neglect, or PMN coupled with unspecified visual neglect form. This interpretation is likely since neglect patients commonly indicate double dissociations with respect to visual neglect. For example, Butler et al. (2004) related severity of peripersonal visual neglect to dorsal stream injury and extrapersonal visual neglect to ventral stream damage. Moreover, isolated forms of PMN in right-hemisphere injured patients may be quite common (see Saevarsson and Kristjánsson, 2013 on no neglect improvement following prism adaptation). Indeed, the literature indicates isolated cases of the affliction where only one modality, such as motor or conceptual, is affected (e.g., Laplane and Degos, 1983; Ortigue et al., 2001). Therefore, Himmelbach and Rossit et al. tested right-hemisphere injured patients that may have suffered from an isolated form of PMN and other forms of non-diagnosed neglect. Furthermore, several authors claim that different neuroanatomical mechanisms may explain isolated forms of neglect within the syndrome (e.g., Chechlacz et al., 2012). Coulthard et al. $(2006,2007)$ argue against the idea that impairments found only in neglect are the sole indication of what the syndrome is. Instead, they assert that neglect is a combination of a group of mental deficits such as impaired spatial memory and directional motor deficits. They explain that PMN can consist of less efficient contralesional reaches and target location on one side, but not to both directions. However, whether and how PMN belongs to the neglect syndrome, should be a central issue when explaining neglect as it affects its assessment and therapy (Saevarsson, 2013b). Indeed, non-sensory factors of movement may be better indicators of poor clinical outcomes than sensory ones (Punt and Riddoch, 2006). PMN and visual feedback are believed to be predictors of successful prism adaptation therapy for neglect (Saevarsson et al., 2009; Striemer and Danckert, 2010a,b; Saevarsson, 2013b; Saevarsson and Kristjánsson, 2013). For instance, Goedert et al. (2014) found bigger improvements on various neglect tests following two weeks of prism adaptation therapy by PMN patients compared to patients suffering from visual neglect without PMN. Similarly, practicing limb movements (Robertson et al., 1992; Pitteri et al., 2013) and increasing contralesional eye movements with prism adaptation intervention improves neglect (Serino et al., 2006). It is also proposed that unspecified frontal and parietal areas play a crucial role in PMN, even if its exact neuroanatomical mechanism is largely not understood. Saevarsson (2013a) reviews 43 studies that apply various assessment 
approaches and concludes that frontal and parietal structures are most commonly injured in PMN. For instance, Vossel et al. (2010) measured a visual and response bias in neglect with the "turned" manual Landmark task. They found that a visual bias in neglect is caused by frontal, parietal, and occipital injury, while caudate nucleus and putamen were associated with PMN. Mattingley et al. (1998) used a leftright response button task to explore these same components. They show that brain lesions in the inferior parietal lobe-not frontal cortex-explain PMN symptoms and suggest that the inferior parietal lobe operates as a sensorimotor interface. In addition, ignorance of PMN aspects of neglect assessment and the methodological limitations of BIT with respect to neuroanatomical underpinnings call our current understanding of neglect into question (Plummer et al., 2003; Saevarsson, 2013a). Lastly, we call for PMN to be systematically addressed (see Mattingley and Driver, 1997; Saevarsson, 2013a for a discussion and suggestions of PMN assessment) in every study on perceptual neglect that requires directional movements because of difficulties in differentiating between the clinical effects of these two subgroups of PMN and visual neglect. One can claim that the critiques of Rossit et al. (2009a) and others are imperfect and that the contralesional directional action components of neglect should remain a part of the standard definition and assessment focus (Saevarsson, 2013a).

\section{ACKNOWLEDGMENTS}

The authors are grateful to the reviewer for helpful comments, and Stella-Viviane Welter, Prof. Ulrike Halsband, Prof. Georg Goldenberg, and Prof. Masud Husain for motivating discussion.

\section{REFERENCES}

Bisiach, E., Geminiani, G., Berti, A., and Rusconi, M. L. (1990). Perceptual and premotor factors of unilateral neglect. Neurology 40, 1278-1281. doi: 10.1212/WNL.40.8.1278

Brewer, B. (1994). Neglect and philosophy. Neuropsychol. Rehabil. 4, 119-122. doi: 10. 1080/09602019408402267

Butler, B. C., Eskes, G. A., and Vandorpe, R. A. (2004). Gradients of detection in neglect: comparison of peripersonal and extrapersonal space. Neuropsychologia 42, 346-358. doi: 10.1016/j. neuropsychologia.2003.08.008
Buxbaum, L. J., Ferraro, M. K., Veramonti, T., Farne, A., Whyte, J., Ladavas, E., et al. (2004). Hemispatial neglect subtypes, neuroanatomy, and disability. Neurology 62, 749-756. doi: 10.1212/01.WNL.0000113730.73031.F4

Cermak, S. A., and Hausser, J. (1989). The behavioral inattention test for unilateral visual neglect: a critical review. Phys. Occup. Ther. Geriatr. 7, 43-53.

Chechlacz, M., Rotshtein, P., and Humphreys, G. W. (2012). Neuroanatomical dissections of unilateral visual neglect symptoms: ALE meta-analysis of lesion-symptom mapping. Front. Hum. Neurosci. 6:230. doi: 10.3389/fnhum.2012.00230

Coulthard, E., Parton, A., and Husain, M. (2006). Action control in visual neglect. Neuropsychologia 44, 2717-2733. doi: 10.1016/j.neuropsychologia. 2005.11.004

Coulthard, E., Parton, A., and Husain, M. (2007). The modular architecture of the neglect syndrome: implications for action control in visual neglect. Neuropsychologia 45, 1982-1984. doi: 10.1016/j.neuropsychologia.2007.01.020

Danckert, J., and Ferber, S. (2006). Revisiting unilateral neglect. Neuropsychologia 44, 987-1006. doi: 10.1016/j.neuropsychologia.2005.09.004

Ghacibeh, G. A., Shenker, J. I., Winter, K. H., Triggs, W. J., and Heilman, K. M. (2007). Dissociation of neglect subtypes with transcranial magnetic stimulation. Neurology 69, 1122-1127. doi: 10.1212/01. wnl.0000276950.77470.50

Gillen, R., Tennen, H., and McKee, T. (2005). Unilateral spatial neglect: relation to rehabilitation outcomes in patients with right hemisphere stroke. Arch. Phys. Med. Rehabil. 86, 763-767. doi: 10.1016/j.apmr.2004.10.029

Goedert, K. M., Chen, P., Boston, R. C., Foundas, A L., and Barrett, A. M. (2014). Presence of motorintentional aiming deficit predicts functional improvement of spatial neglect with prism adaptation. Neurorehabil. Neural Repair 28, 483-493. doi: $10.1177 / 1545968313516872$

Goodale, M. A., Milner, A. D., Jakobson, L. S., and Carey, D. P. (1990). Kinematic analysis of limb movements in neuropsychological research: subtle deficits and recovery funcion. Can. J. Psychol. 44, 180-195. doi: 10.1037/h0084245

Halligan, P. W., and Marshall, J. C. (1989). Laterality of motor response in visuo-spatial neglect: a case study. Neuropsychologia 27, 1301-1307. doi: 10.1016/0028-3932(89)90042-0

Heilman, K. M., Bowers, D., Valenstein, E., and Watson, R. T. (1987). "Hemispace and hemispatial neglect," in Neuropsychological and Neuropsychological Aspects of Spatial Neglect, ed M. Jeannerod (New York, NY: Elsevier Science Publishers Company), 115-150. doi: 10.1016/ S0166-4115(08)61711-2

Heilman, K. M., Valenstein, E., Rothi, L. J. G., and Watson, R. T. (2008). "Intentional motor disorders and the apraxias," in Neurology in Clinical Practice: Principles of Diagnosis and Management, eds W. G. Bradley and R. B. Daroff (Philadelphia, PA: Butterworth-Heinemann), 121-132. doi: 10.1016/B978-0-7506-7525-3.50012-1

Himmelbach, M., and Karnath, H. O. (2003). Goaldirected hand movements are not affected by the biased space representation in spatial neglect. J. Cogn. Neurosci. 15, 972-980. doi: 10.1162/ 089892903770007362
Himmelbach, M., Karnath, H. O., and Perenin, M. T. (2007). Action control is not affected by spatial neglect: a comment on Coulthard et al. Neuropsychologia 45, 1979-1981. discussion: 1982-1984. doi: 10.1016/j.neuropsychologia.2006. 12.009

Hjaltason, H., and Saevarsson, S. (2007). Unilateral spatial neglect: a review of symptoms, frequency diagnosis and prognosis. Iceland. Med. J. 93, 681-687.

Husain, M., and Kennard, C. (1996). Visual neglect associated with frontal lobe infarction. J. Neurol. 243, 652-657. doi: 10.1007/BF00878662

Husain, M., Mattingley, J. B., Rorden, C., Kennard, C., and Driver, J. (2000). Distinguishing sensory and motor biases in parietal and frontal neglect. Brain 123, 1643-1659. doi: 10.1093/brain/123.8.1643

Karnath, H.-O. (2014). "Neglect," in Klinische Neuropscyhologie - Kognitive Neurologie, eds H.-O. Karnath, G. Goldenberg, and W. Ziegler (Stuttgart: Thieme Verlag), 198-212.

Karnath, H.-O., Berger, M. F., Kuker, W., and Rorden, C. (2004). The anatomy of spatial neglect based on voxelwise statistical analysis: a study of 140 patients. Cereb. Cortex 14, 1164-1172. doi: 10.1093/cercor/bhh076

Karnath, H.-O., Ferber, S., and Himmelbach, M. (2001). Spatial awareness is a function of the temporal not the posterior parietal lobe. Nature 411, 950-953. doi: 10.1038/35082075

Karnath, H.-O., Himmelbach, M., and Rorden, C. (2002). The subcortical anatomy of human spatial neglect: putamen, caudate nucleus, and pulvinar. Brain 125, 350-360. doi: 10.1093/brain/awf032

Kim, E. J., Lee, B., Jo, M. K., Jung, K., You, H., Lee, B. H., et al. (2013). Directional and spatial motor intentional disorders in patients with right versus left hemisphere strokes. Neuropsychology 27, 428. doi: 10.1037/a0032824

Kimberg, D. Y., Coslett, H. B., and Schwartz, M F. (2007). Power in voxel-based lesion-symptom mapping. J. Cogn. Neurosci. 19, 1067-1080. doi: 10.1162/jocn.2007.19.7.1067

Konczak, J., and Karnath, H. O. (1998). Kinematics of goal-directed arm movements in neglect: control of hand velocity. Brain Cogn. 37, 387-403. doi: 10.1006/brcg.1998.1004

Làdavas, E., Umiltà, C., Ziani, P., Brogi, A., and Minarini, M. (1993). The role of right side objects in left side neglect: a dissociation between perceptual and directional motor neglect. Neuropsychologia 31, 761-773. doi: 10.1016/00283932(93)90127-L

Laplane, D., and Degos, J. D. (1983). Motor neglect. J. Neurol. Neurosurg. Psychiatry 46, 152-158. doi: 10.1136/jnnp.46.2.152

Mattingley, J. B., and Driver, J. (1997). “Distinguishing sensory and motor deficits after parietal damage: an evaluation of response selection biases in unilateral neglect," in Parietal Contributions to Orientation in 3D Space, P. Thier and H.-O. Karnath (Heidelberg: Springer), 309-338. doi: 10.1007/978-3-642-60661-8_18

Mattingley, J. B., Husain, M., Rorden, C., Kennard, C., and Driver, J. (1998). Motor role of human inferior parietal lobe revealed in unilateral neglect patients. Nature 392, 179-182. doi: 10.1038/32413

Mort, J. M., Malhotra, P., Mannan, S. K., Rorden, C., Pambakian, A., Kennard, C., et al. (2003). The 
anatomy of visual neglect. Brain 126, 1986-1997. doi: 10.1093/brain/awg200

Muggleton, N. G., Postma. P., Moutsopoulou, K., Nimmo-Smith. I., Marcel, A., and Walsh, V. (2006). TMS over right posterior parietal cortex induces neglect in a scene-based frame of reference. Neuropsychologia 44, 1222-1229. doi: 10.1016/j.neuropsychologia.2005.10.004

Ortigue, S., Viaud-Delmon, I., Annoni, J. M., Landis, T., Michel, C., Blanke, O., et al. (2001). Pure representational neglect after right thalamic lesion. Ann. Neurol. 50, 401-404. doi: 10.1002/ana.1139

Pitteri, M., Arcara, G., Passarini, L., Meneghello, F., and Priftis, K. (2013). Is two better than one? Limb activation treatment combined with contralesional arm vibration to ameliorate signs of left neglect. Front. Hum. Neurosci. 7:460. doi: 10.3389/fnhum.2013.00460

Plummer, P., Morris, M. E., and Dunai, J. (2003). Assessment of unilateral neglect. Phys. Ther. 83, 732-740.

Punt, T. D., and Riddoch, M. J. (2006). Motor neglect: implications for movement and rehabilitation following stroke. Disabil. Rehabil. 28, 857-864. doi: 10.1080/09638280500535025

Robertson, I. H., North, N. T., and Geggie, C. (1992). Spatiomotor cueing in left unilateral neglect: three case studies of its therapeutic effects. J. Neurol. Neurosurg. Psychiatry 55, 799-805. doi: 10.1136/ jnnp.55.9.799

Rorden, C., Karnath, H. O., and Bonilha, L. (2007). Improving lesion-symptom mapping. J. Cogn. Neurosci. 19, 1081-1088. doi: 10.1162/jocn.2007. 19.7.1081

Rossit, S., Malhotra, P., Muir, K., Reeves, I., Duncan, G., Birschel, P., et al. (2009b). The neural basis of visuomotor deficits in hemispatial neglect. Neuropsychologia 47, 2149-2153. doi: 10.1016/j.neuropsychologia.2009.04.015

Rossit, S., Malhotra, P., Muir, K., Reeves, I., Duncan, G., Livingstone, K., et al. (2009a).
No neglect-specific deficits in reaching tasks. Cereb. Cortex 19, 2616-2624. doi: 10.1093/cercor/ bhp016

Saevarsson, S. (2013a). Motor response deficits of unilateral neglect: assessment, therapy, and neuroanatomy. Appl. Neuropsychol. Adult 20, 292-305. doi: 10.1080/09084282.2012.710682

Saevarsson, S. (2013b). Prism adaptation theory in unilateral neglect: motor and perceptual components. Front. Hum. Neurosci. 7:728. doi: 10.3389/ fnhum.2013.00728

Saevarsson, S., Halsband, U., and Kristjánsson, Á. (2011). Designing rehabilitation programs for neglect: could 2 be more than $1+1$ ? Appl. Neuropsychol. 18, 95-106. doi: 10.1080/09084282. 2010.547774

Saevarsson, S., Jóelsdóttir, S., Hjaltason, H., and Kristjánsson, A. (2008). Repetition of distractor sets improves visual search performance in hemispatial neglect. Neuropsychologia 46, 1161-1169. doi: 10.1016/j.neuropsychologia.2007.10.020

Saevarsson, S., and Kristjánsson, Á. (2013). A note on Striemer and Danckert's theory of prism adaptation in unilateral neglect. Front. Hum. Neurosci. 7:44. doi: 10.3389/fnhum.2013.00044

Saevarsson, S., Kristjánsson, Á., Hildebrandt, H., and Halsband, U. (2009). Prism adaptation improves visual search in hemispatial neglect. Neuropsychologia 47, 717-725. doi: 10.1016/j. neuropsychologia.2008.11.026

Serino, A., Angeli, V., Frassinetti, F., and Làdavas, E. (2006). Mechanisms underlying neglect recovery after prism adaptation. Neuropsychologia 44, 1068-1078. doi: 10.1016/j.neuropsychologia. 2005. 10.024

Striemer, C. L., and Danckert, J. (2010a). Dissociating perceptual and motor effects of prism adaptation in neglect. Neuroreport 21, 436-441. doi: 10.1097/WNR.0b013e328338592f

Striemer, C. L., and Danckert, J. (2013). The influence of prism adaptation on perceptual and motor components of neglect: a reply to Saevarsson and Kristjánsson. Front. Hum. Neurosci. 7:255. doi: 10.3389/fnhum.2013.00255

Striemer, C. L., and Danckert, J. A. (2010b). Through a prism darkly: re-evaluating prisms and neglect. Trends Cogn. Sci. 14, 308-316. doi: 10.1016/j.tics. 2010.04.001

Vossel, S., Eschenbeck, P., Weiss, P. H., and Fink, G. R. (2010). The neural basis of perceptual bias and response bias in the Landmark task. Neuropsychologia 48, 3949-3954. doi: 10.1016/j. neuropsychologia.2010.09.022

Watson, R. T., Miller, B. D., and Heilman, K. M. (1978). Nonsensory neglect. Ann. Neurol. 3, 505-508. doi: 10.1002/ana.410030609

Wilson, B., Cockburn, J., and Halligan, P. W. (1987). Behavioral Inattention Test. Thomas Valley: Bury St. Edmunds.

Conflict of Interest Statement: The authors declare that the research was conducted in the absence of any commercial or financial relationships that could be construed as a potential conflict of interest.

Received: 24 March 2014; accepted: 13 September 2014; published online: 15 October 2014.

Citation: Saevarsson S, Eger S and Gutierrez-Herrera $M$ (2014) Neglected premotor neglect. Front. Hum. Neurosci. 8:778. doi: 10.3389/fnhum.2014.00778

This article was submitted to the journal Frontiers in Human Neuroscience.

Copyright (C) 2014 Saevarsson, Eger and GutierrezHerrera. This is an open-access article distributed under the terms of the Creative Commons Attribution License (CC BY). The use, distribution or reproduction in other forums is permitted, provided the original author(s) or licensor are credited and that the original publication in this journal is cited, in accordance with accepted academic practice. No use, distribution or reproduction is permitted which does not comply with these terms. 